\title{
Quality of life of pancreas transplant recipients
}

\author{
C. L. Zehrer ${ }^{1}$ and C. R. Gross ${ }^{2}$ \\ ${ }^{1}$ Clinical Research Center, Department of Nursing Services; and ${ }^{2}$ School of Nursing and College of Pharmacy, University Hospital and \\ Clinic, University of Minnesota, Minneapolis, USA
}

Summary. The quality of life outcome of 131 pancreas transplant recipients who were 1 to 11 years posttransplant were studied. Patients with a functioning pancreas graft $(n=65)$ described their current quality of life and rated their health significantly more favourably than those with non-functioning grafts $(n=66)$. For example, of those patients with a functioning pancreas graft, $68 \%$ expressed overall satisfaction with their life, $89 \%$ felt healthier since their transplant, and 78\% reported that they could care for themselves and their routine daily activities. In contrast, of those patients without a functioning graft, only $48 \%$ expressed overall satisfaction with life $(p<0.01)$, only $25 \%$ felt healthier since their transplant $(p<0.001)$, and only $56 \%$ indicated they could care for themselves and their daily activities $(p<0.001)$. Regardless of graft function, the majority of patients were comfortable with their decision to have the transplant, and most of the patients with pancreas graft function reported that they would have another transplant if their graft failed. While successful pancreas transplantation may not elevate all diabetic patients to the level of health and function of the general population, these patients report a significantly better quality of life than do those patients who remain diabetic.

Key words: Pancreas transplant - Quality of life

\section{Introduction}

There are approximately 500,000 individuals in the United States (National Diabetes Data Group 1985) and many times that number worldwide with Type 1 (insulindependent) diabetes mellitus who are at risk of developing the various complications of that disease. The long-term complications of diabetes can be severe, and it is the third leading cause of death by disease, as well as the leading cause of blindness in the United States. Diabetic individuals are twice as likely to have coronary heart disease or a stroke, five times more likely to develop gangrene, and 17 times more likely to have renal failure than the general population. Life expectancies for diabetic individuals are substantially lower than that of the general population (National Diabetes Data Group 1985). Because many researchers believe that maintaining glucose levels in the near-normal range may delay or prevent diabetic complications (Raskin and Rosenstock 1986; Diabetes Control and Complications Trial Research Group 1988), pancreas transplantation is being performed in order to normalize blood sugar in individuals with Type 1 diabetes (Sutherland et al 1988).

When successful, pancreas transplantation has been shown to maintain normal blood glucose levels, normal glycosylated haemoglobin levels, and an insulinindependent state (Sutherland et al 1981; Pozza et al 1985; Robertson et al 1989). Although a successful pancreas transplant can prevent the occurrence of diabetic nephropathy in a simultaneously transplanted kidney (Bohman et al 1985; Bilous et al 1987), the effect of pancreas transplantation on established complications has been variable and not very dramatic (Ramsey et al 1988; Kennedy et al 1990). Although further research may show that a successful pancreas transplant can prevent diabetic complications, prophylactic transplants have not been done because of the uncertain risks of immunosuppression coupled with the inability to predict who will develop diabetic lesions before they are actually present. The benefits of a pancreas transplant, however, may not be restricted to its ability to influence retinopathy, neuropathy, nephropathy, and the other tissue-associated complications that can be assessed by finite and objective end points. Among these hypothesized benefits is the impact of pancreas transplantation on important and often sensitive aspects of day-to-day living which cannot be measured by the usual laboratory and clinical measurements. These aspects, termed "quality of life", are also important to research in assessing the impact of medical technology on the rehabilitation of the treated patient (Najman and Levine 1981). The potential benefits of transplantation, such as retardation of diabetic complications and improvements in life style, must be balanced against both the risks of surgery and the adverse effects of steroids and other immunosuppressive drugs. 
Currently, there are very few reports on quality of life following pancreas transplantation as assessed by psychosocial measurements (Nakache et al 1989; Voruganti and Sells 1989; Corry and Zehr 1990). These studies have been cross-sectional, utilized small numbers of subjects, and only included patients who also received a kidney transplant. In general, the studies show various indicators of quality of life to be higher for patients after a successful combined pancreas/kidney transplant than for those who received a kidney transplant alone or those whose pancreas grafts have failed. Nakache et al (1989) from Sweden reported significantly more diabetic recipients of pancreas/kidney transplants were working full-time, had lost fewer work days, and had fewer hospitalizations than recipients of kidney transplants alone. Subjectively, $80 \%$ of the recipients of combined transplants reported that they had the same or better quality of life as they had before the onset of renal failure, compared to only $50 \%$ of recipients of kidney transplants alone. Voruganti and Sells (1989) from UK reported that recipients of pancreas/kidney transplants showed significantly better adjustment, especially in the domestic, vocational, and sexual spheres of life, and had improved self image, a significant increase in identity stability, and felt more in control of their own destiny than did those individuals who received only kidney transplants. Corry and Zehr (1990) from the US reported that patients with a functioning pancreas transplant had subjectively improved neuropathy (35\%), lessened severity of symptoms of enteropathy (96\%), improvements in mood, and experienced considerably less fatigue.

\section{Subjects and methods}

We report here the results of an assessment of quality of life in both successful and failed pancreas transplants at the University of Minnesota. This study differs from previously reported research not only in the types of measurements that were used but also in including non-uraemic, non-kidney transplant recipients and in making the comparison between those whose diabetes has been continuously ameliorated up to the time of the survey vs those who reverted to the diabetic state or whose surgery failed from the onset. The specific aim of this study was to describe the quality of life outcome of all surviving adult patients $(n=138)$ who had received pancreas transplantation for Type 1 diabetes at the University of Minnesota Hospital and Clinic, regardless of the surgical technique (bladder or other drainage, with or without auxiliary kidney), or current graft function. To participate, patients were required to be at least one year post-pancreas transplant at the time of study. In the analysis, the status of current graft function was used to create two patient groups. The group with functioning grafts $(n=65)$ consisted of all patients who were insulin-independent at the time of the study. The group without functioning grafts $(n=66)$ consisted of all patients currently requiring insulin. This latter group contained patients who had never achieved insulin independence as well as patients who had pancreatic graft function after surgery but later lost this function.

Quality of life following pancreas transplantation was assessed by patient self-report. The questionnaire (approved by the Committee on the Use of Human Subjects in Research at the University of Minnesota Hospital and (linic) was mailed to 138 transplant recipients with a covering letter explaining the study, a consent form, and a stamped, self-addressed envelope. A reply card was also enclosed so patients could notify the researchers if they needed assistance to complete the questionnaire or if they did not wish to participate. One blind patient requested a telephone interview in lieu of the mailed questionnaire. Completed questionnaires were returned by 131 patients for a $95 \%$ response rate.
The questionnaire included demographics, subjective quality of life indicators of satisfaction, general affect and general health measures, as well as transplant and diabetes-specific symptoms and attitudes. Specific questions regarding perceptions of benefits and attitudes about transplantation were asked since patients who are undergoing evaluation for a pancreas transplant are interested in what benefits other patients have experienced.

The approach used in this study has been derived from the works of Campbell, Converse and Rodgers (1976). Simmons (1987), and Evans (1985). Within this study's framework, the items which are considered to represent quality of life are overall satisfaction with life and general affect, which are combined into an Index of Well-Being (Campbell et al 1976). Overall satisfaction with life was determined by a single question, recorded on a seven-point scale from complete satisfaction to complete dissatisfaction. General affect was assessed by patient responses to an eight-item semantic differential scale which was summed to create an Index of General Affect (Campbell et al 1976). Life satisfaction was subdivided into domains such as health, work, and personal relationships, each of which was expected to influence overall satisfaction with life. These subjective items are assumed to correspond to the patient's personal and internal evaluation of his or her life. In this study, potentially important influences on quality of life were considered to be the ability to carry out activities of daily living (dress, feed, care for basic personal needs without assistance) and the ability to perform at work. These last items are sometimes viewed as representing external or more objective components of quality of life. It is hypothesized that pancreas transplantation as therapy for diabetes will have its greatest impact on patient health, but that the patient's health will in tum exert influence on many other domains, such as work and personal relationships, and will thus be an important influence on the patient's evaluations of his or her quality of life.

Ability to carry out activities of daily living was assessed using a version of the Kamofsky Index (1949) modified for self-report (Evans et al 1985). Questions regarding attitudes towards transplantation, and questions about health care burden and satisfaction were developed for this study. Global quality of life measures, overall satisfaction with life, and general affect were assessed using standard questions which have national norms (Campbell et al 1976). Satisfaction with life, health, work, and personal relationships was assessed by questions similar to those used by Simmons (1987) and Evans (1985) in studies of kidney or heart transplant patients.

Staistical methods. Patients were grouped according to pancreas graft function. These groups were compared using t-tests or Chi-square tests, depending on the level of measurement of the variable of interest. Results were considered statistically significant at the $p<0.05$ level.

\section{Results}

Table 1 summarizes the sociodemographic and medical characteristics of the 131 participating patients grouped according to functioning pancreas graft (insulinindependent) or non-functioning graft (insulin-dependent). There were no statistically significant differences between the functioning graft and non-functioning graft groups for any of the sociodemographic items.

The data indicate that patients' evaluations of their current health were significantly related to the status of their pancreas graft (Table 2). Patients were asked to rate their current health and compare their health now to their health before the transplant. Most patients with functioning grafts rated their current health as good $(61 \%)$ or excellent $(10 \%)$, while patients with non-functioning grafts were more apt to describe their health as fair or poor, and no patients in the latter group considered their health to be excellent $(p<0.001)$. Similarly, patients with graft function were more likely to view their health as 
Table 1. Sociodemographic and medical characteristics of patients according to graft function group.

\begin{tabular}{|c|c|c|c|}
\hline \multicolumn{2}{|c|}{ Factors } & $\begin{array}{c}\begin{array}{c}\text { Function } \\
(n=65)\end{array} \\
\end{array}$ & $\begin{array}{c}\begin{array}{c}\text { Non-function } \\
(n=66)\end{array} \\
\end{array}$ \\
\hline \multicolumn{2}{|c|}{ Sociodemographic } & $N(\%)$ & $N(\%)$ \\
\hline \multirow[t]{2}{*}{ Sex } & Female & $47(72)$ & $40(61)$ \\
\hline & Male & $18(28)$ & $39(39)$ \\
\hline \multicolumn{4}{|c|}{ Marital status } \\
\hline & Married & $38(59)$ & $32(49)$ \\
\hline & Never married & $15(23)$ & $19(29)$ \\
\hline & Other & $11(17)$ & $14(22)$ \\
\hline \multicolumn{4}{|c|}{ Education - highest level } \\
\hline & Grade $9-11$ & $0(0)$ & $2(3)$ \\
\hline & High school & $14(22)$ & $12(18)$ \\
\hline & Some college & $31(48)$ & $28(42)$ \\
\hline & College degree $(\mathrm{s})$ & $19(30)$ & $24(36)$ \\
\hline \multicolumn{4}{|c|}{ Paid employment } \\
\hline & Full-time & $24(37)$ & $21(32)$ \\
\hline & Part-time & $5(8)$ & $8(12)$ \\
\hline & Not employed & $36(55)$ & $37(56)$ \\
\hline \multicolumn{4}{|c|}{ Age in years } \\
\hline & Median (range) & $37(24-51)$ & $35(21-55)$ \\
\hline \multicolumn{4}{|c|}{ Medical } \\
\hline \multicolumn{4}{|c|}{ No. of pancreas graft surgeries } \\
\hline & 1 & $53(81)$ & $51(78)$ \\
\hline & 2 & $9(14)$ & $9(14)$ \\
\hline & 3 & $3(5)$ & $5(8)$ \\
\hline \multicolumn{4}{|c|}{ Time since last pancreas transplant $\mathrm{a}^{\mathrm{a}}$} \\
\hline & Mean (months) & 33 & 52 \\
\hline & Median & 27 & 39 \\
\hline \multicolumn{4}{|c|}{ Kidney graft } \\
\hline & Functioning & $37(58)$ & $30(48)$ \\
\hline & Non-functioning & $0(0)$ & $2(3)$ \\
\hline & No auxiliary kidney & $27(42)$ & $31(49)$ \\
\hline \multicolumn{4}{|c|}{ Days sick in bed in last month ${ }^{b}$} \\
\hline & 0 & $49(75)$ & $37(56)$ \\
\hline & $1-7$ & $15(32)$ & $18(27)$ \\
\hline & $8-14$ & $1(2)$ & $6(9)$ \\
\hline & $15+$ & $0(0)$ & $5(8)$ \\
\hline
\end{tabular}

a $p<0.001$, t-test

$\mathrm{b}_{p<0.05 \text {, Chi square }}^{p<0.001,1-s t}$

having improved since the transplant $(89 \%$ vs $25 \%$, $p<0.001$ ), and were also more likely to view their ability to accomplish daily activities as normal or nearly normal $(p<0.01)$.

Subjective indicators of quality of life were also significantly related to the status of the pancreas graft. When asked about satisfaction with life, $68 \%$ of those patients with a functioning graft were satisfied with life, vs $48 \%$ of patients in the non-functioning group $(p<0.01)$. The average scores for satisfaction, the Index of General Affect, and the Index of Well-Being for these patient groups are listed in Table 3. All scores are graded so that highest scores represent more positive ratings.

Several questions were asked regarding patients' attitudes toward pancreas transplantation. Of the functioning graft group, $89 \%$ of patients indicated they were comfortable with their decision to undergo pancreas transplantation, and $68 \%$ stated they would undergo another pancreas transplant procedure if their graft failed. Even the majority of patients who had lost graft function (72\%) were also comfortable with their decision to have a pancreas transplant. Moreover, $52 \%$ of the patients in this group stated they would undergo another pancreas
Table 2. Health and ability to perform daily activities according to graft function.

\begin{tabular}{|c|c|c|}
\hline & $\begin{array}{c}\text { Function } \\
(n=65)\end{array}$ & $\begin{array}{c}\text { Non-function } \\
(n=66)\end{array}$ \\
\hline & $N(\%)$ & $N(\%)$ \\
\hline \multicolumn{3}{|c|}{ Would you say your health is ${ }^{a}$} \\
\hline Excellent & $6(10)$ & $0(0)$ \\
\hline Good & $38(61)$ & $15(23)$ \\
\hline Fair & $16(26)$ & $31(48)$ \\
\hline Poor & $2(3)$ & $18(28)$ \\
\hline \multicolumn{3}{|c|}{$\begin{array}{l}\text { Compared to before your transplant, } \\
\text { would you say you are now: }\end{array}$} \\
\hline More healthy & $57(89)$ & $14(25)$ \\
\hline Less healthy & $4(6)$ & $21(37)$ \\
\hline About as healthy & $3(5)$ & $22(39)$ \\
\hline
\end{tabular}

Karnofsky Category ${ }^{c}$

No complaints: no evidence of disease 11 (18) 4 (6)

Able to carry out normal activity:

minor signs and symptoms of disease $16(25) \quad 14(22)$

Normal activity with effort: some signs

and symptoms of disease

$22(35) \quad 18(28)$

Cares for self, but unable to carry on normal activity

Requires occasional assistance, but

cares for most of own needs

$7(11) \quad 6(8)$

Requires considerable assistance and

frequent medical care

Disabled; requires special care and

assistance

$3(5)$

14 (22)

2 (3) $6(9)$

$2(3) \quad 3(5)$

${ }_{b}^{a} p<0.001$, t-test

b $p<0.001$, Chi square

$c_{p<0.01 \text {, t-test }}$

transplant procedure. Only $10 \%$ of patients in the functioning pancreas graft group and $17 \%$ of patients in the non-functioning pancreas graft group stated they would not have a second pancreas transplant, while $23 \%$ and $31 \%$ respectively, were undecided. Primary reasons cited for indecision or lack of interest in undergoing another pancreas transplant included financial considerations, side effects of the immunosuppressive drugs, and excessive stress on their families. Interestingly, most patients whose reluctance was related to the side effects of immunosuppressive medications indicated that they would consider a pancreas transplant if and when a kidney transplant became necessary.

To assess whether patients would recommend pancreas transplant, they were asked, "If a close friend had problems like yours and wanted a pancreas transplant in the future, would you encourage him or discourage him from considering pancreas transplant?" Virtually $100 \%$ of the patients with a functioning pancreas graft and $86 \%$ of patients with a non-functioning pancreas graft would encourage a close friend with similar complications to consider pancreas transplant.

The functioning pancreas transplant group was asked if it was easier to manage their diabetes or their transplant on a day-to-day basis. Ninety-two percent reported that it was easier to take immunosuppressive medications and manage the transplant than it was to take insulin injections and manage their diabetes $(p<0.001)$. When asked which condition was more demanding on their families' time and energy, the transplant or diabetes, $63 \%$ of this group felt that diabetes was more demanding, $29 \%$ 
Table 3. Average quality of life scores according to graft function.

\begin{tabular}{|c|c|c|c|}
\hline & $\begin{array}{l}\text { Function } \\
(n=65)\end{array}$ & $\begin{array}{c}\text { Non-function } \\
(n=66)\end{array}$ & $\begin{array}{l}\text { National sample } \\
\text { aduit reference } \\
\text { population } \\
(n=2164) \\
\end{array}$ \\
\hline $\begin{array}{l}\text { Index of well-being } \\
\text { (range, } 2.1-14.7 \text { ) }\end{array}$ & 10.82 & $9.36^{\mathrm{a}}$ & 11.7 \\
\hline $\begin{array}{c}\text { Index of general affect } \\
(\text { range, 1-7) }\end{array}$ & 5.28 & $4.66^{b}$ & 5.68 \\
\hline $\begin{array}{l}\text { Overall life satisfaction } \\
\text { (range, } 1-7 \text { ) }\end{array}$ & 4.98 & $4.26^{b}$ & 5.55 \\
\hline \multicolumn{4}{|l|}{ Satisfaction with: } \\
\hline $\begin{array}{l}\text { Health } \\
\text { (range, 1-7) }\end{array}$ & 5.06 & $3.68^{a}$ & \\
\hline $\begin{array}{l}\text { Current treatment } \\
\text { (range, 1-5) }\end{array}$ & 3.37 & $2.35^{\mathrm{a}}$ & \\
\hline $\begin{array}{l}\text { Performance at work, } \\
\text { school and home } \\
\text { (range, 1-5) }\end{array}$ & 2.46 & $1.82^{\mathrm{c}}$ & \\
\hline $\begin{array}{l}\text { Personal relationships } \\
\text { (range, 1-5) }\end{array}$ & 2.82 & 2.51 & \\
\hline $\begin{array}{l}\text { Leisure } \\
\text { (range, 1-5) }\end{array}$ & 2.65 & 2.32 & \\
\hline $\begin{array}{l}\text { Sex life } \\
\text { (range, 1-5) }\end{array}$ & 2.14 & 2.08 & \\
\hline
\end{tabular}

a $p<0.001$, t-test

b $p<0.01$, t-test

$c_{p<0.05 \text {, t-test }}^{p}$

felt that the two were equally demanding, and only $9 \%$ reported that the transplant was more demanding than the management of their diabetes $(p<0.05)$.

Patients with pancreas graft function were asked about their perceptions of the benefits of having the pancreas transplant. This group described the benefits to be normalization of blood sugar, and freedom from insulin injections, insulin reactions, and a specialized diet. They rated feeling better physically and psychologically to be a great benefit, as well as reporting feeling more hopeful about the future and having a more positive outlook on life. In addition, more than $90 \%$ of the group perceived that they had a decreased chance of requiring amputations and that the pancreas transplant had already prevented further diabetic kidney damage.

\section{Discussion}

We have attempted to assess the effects of pancreas transplantation from the patients' perspectives. In this cross-sectional study of 131 patients representing a consecutive series of pancreas transplant recipients, we found that successful pancreas graft function was related to more positive levels on a number of indicators of global life quality, health-related quality of life outcomes, positive attitudes toward the procedure, and a large number of perceived benefits.

The functioning and non-functioning pancreas graft groups were approximately the same in size and comparable in terms of age and severity of complications. The use of standardized scales facilitated comparisons between the groups as well as comparison to a general reference population. In this study, more positive outcomes were perceived by the functioning pancreas graft group. This group reported more positive outcomes in terms of subjective assessments of quality of life, ratings of health, and their ability to perform daily activities. The functioning pancreas graft group reported being more satisfied with life, and having better health than did the non-functioning pancreas graft group.

The cross-sectional and observational nature of this study, however, limits our ability to directly attribute these positive attitudes to pancreas transplant. It is possible that at least some of the observed differences between the functioning pancreas graft and nonfunctioning pancreas graft groups were due to a negative outcome of transplantation on those with graft failure. The only evidence we have to refute this hypothesis is the willingness of many patients who experienced pancreas graft failure to repeat the procedure. Another limitation deserving of mention is the impact of the procedure on patient survival. Patient survival rates post-pancreas transplant are high (Sutherland et al 1989). At the University of Minnesota, patient survival at one year post-transplant was $96 \%$ in recipients of pancreas transplants alone, $93 \%$ in recipients of a pancreas after a kidney, and $89 \%$ in recipients of a simultaneous pancreas/kidney transplant (Gruessner et al 1990). While some deaths can be attributed to the transplant procedure, for some patients, particularly those with severe neuropathy, a successful pancreas transplant may actually improve their chances for survival. In a recent analysis at the University of Minnesota of patients with abnormal autonomic function (Navarro et al 1990), patients with a functioning pancreas transplant had better survival rates than patients with a failed pancreas transplant and, on long-term follow-up, better rates than patients who had not undergone pancreas transplantation. Statistical assessments, however, cannot adequately balance the death of one patient with improvements in quality of life for others, and this risk must be conveyed to patients contemplating the procedure.

Prospective long-term follow-up studies involving control groups of diabetic individuals not desiring a pancreas transplant, matched for duration and severity of complications with the pancreas transplant group at entry, are needed to show both the positive and negative impact of pancreas transplantation on quality of life, particularly in those patients in whom the pancreas graft fails. A comparison between patients who do not undergo a pancreas transplant with those who do undergo a pancreas transplant but are without graft function will show the negative impact that surgery and immunosuppression can have on those whose graft fails. While it is clear from the results of our survey that recipients of successful grafts are likely to feel that their quality of life is much improved by the pancreas transplant, only a prospective study with pre-transplant baselines could estimate the magnitude of both the benefits and the potential negative effects. Such studies would assist future patients to weigh the benefit to risk ratio of pancreas transplantation, and help them make responsible decisions about this procedure as a treatment for Type 1 diabetes.

Acknowledgements. This work was supported by a grant from the National Association of Research Nurses and Dietitians and grant M01 RR00400 from the National Center of Research Resources, 
National Institutes of Health, Bethesda, MD. We also wish to acknowledge the expertise of Ms. K. Steinmeyer in the preparation of this manuscript.

\section{References}

Bilous RW, Mauer SM, Sutherland DER, Steffes MW (1987) Glomerular structure and function following successful pancreas transplantation for insulin-dependent diabetes mellitus. Diabetes 36:43A

Bohman SO, Tyden G, Wilezek A (1985) Prevention of kidney graft diabetic nephropathy by pancreas transplantation in man. Diabetes 34:306-308

Campbell A, Converse PE, Rodgers NL (1976) The quality of American life: perceptions, evaluations, and satisfactions. Russell Sage Foundation: New York, pp 23-95

Corry RJ, Zehr P (1990) Quality of life in diabetic recipients of kidney transplants is better with the addition of the pancreas. Clin Transplantation 4:238-241

DCCT Research Group (1988) Are continuing studies of metabolic control and microvascular complications in insulin-dependent diabetes mellitus justified? N Eng1 J Med 318:246-250

Evans RW, Manninen DL, Garrison LP, Hart LG, Blazz CR, Gutman RA, Hull AR, Lowrie EG (1985) The quality of life of patients with end-stage renal disease. N Engl J Med 312:553-559

Gruessner RWG, Dunn DL, Tzardis PJ, Tomadze G, Moudry-Munns KC, Matas AJ, Najarian JS, Sutherland DER (1990) Simultaneous pancreas and kidney transplants versus single kidney transplants and previous kidney transplants in uremic patients and single pancreas transplants in nonuremic diabetic patients: comparison of rejection, morbidity, and long-term outcome. Transpl Proc $22: 622-623$

Karnofsky DA, Burchenal JH (1949) The evaluation of chemotherapeutic agents. In MacLeod CM (ed) Evaluation of chemotherapeutic agents. Columbia University Press, New York, pp 191-205

Kennedy WR, Navarro X, Goetz FC, Sutheriand DER, Najarian IS (1990) The effects of pancreas transplantation on diabetic neuropathy. N Engl J Med 322:1031-1037

Najman JM, Levine S (1981) Evaluating the impact of medical and technologies on the quality of life: a review and critique. Soc Sci Med 15:107-115

Nakache R, Tyden G, Groth GC (1989) Quality of life in diabetic patients after combined pancreas-kidney or kidney transplantation. Diabetes 38:40-42

National Diabetes Data Group (1985) Diabetes in America: diabetes data compiled 1984. Bethesda, MD: Department of Health and Human Services. 1-1-6 (NIH Publication No. 85-1468)

Navarro X, Kennedy WR, Loewenson RB, Sutherland DER (1990) Influence of pancreas transplantation on cardiorespiratory reflexes, nerve conduction, and mortality in diabetes mellitus. Diabetes 39:802-806

Pozza G, Bosi E, Secchi A, Piatti PM, Touraine SL, Gelet A, Ponticol A, Dubernard JM, Traeger J (1985) Metabolic control of type I (insulin dependent) diabetes after pancreas transplantation. $\mathrm{Br}$ Med J 291:510-513

Ramsey RC, Goetz FG, Sutherland DER, Mauer SM, Robinson LL, Cantrill HL, Knobloch WH, Najarian JS (1988) Progression of diabetic retinoathy after pancreas transplantation for insulindependent diabetes mellitus. N Engl J Med 318:208-214

Raskin P, Rosenstock I (1986) Blood glucose control and diabetic complications. Ann Intern Med 105:254-263

Robertson RP, Abid M, Sutherland DER, Diem P (1989) Glucose homeostasis and insulin secretion in human recipients of pancreas transplantation. Diabetes 38:97-98

Simmons RG, Klein SD, Simmons RL (1987) Gift of Life: The effect of organ transplantation on individual, family and societal dynamics. Transaction Inc: New Brunswick NJ

Sutherland DER, Dunn DL, Goetz FC, Kennedy W, Ramsey RC, Steffes MW, Mauer SM, Guessner R, Moudry-Munns KC, Morel P, Viste A, Robertson RP. Najarian JS (1989) A 10 year experience with 290 pancieas transplants at a single institution. Ann Surg $210: 274-285$
Sutherland DER, Kendall DM, Moudry KC, Navarro X, Kennedy WR, Ramsey RC, Steffes MW, Mauer SM, Goetz FC, Dunn DL, Najarian JS (1988) Pancreas transplantation in nonuremic type I diabetic recipients. Surgery 104:453-463

Sutherland DER, Moudry-Munns KC, Gillingham K (1990) Pancreas transplantation: report from the International Registry and a preliminary analysis of United States results from the new united network for organ sharing (UNOS) registry. In: Terasaki P (ed) Clinical transplants. UCLA Tissue Typing Laboratory, Los Angeles, pp 19-43

Sutherland DER, Najarian JS, Greenberg BZ, Senske BJ, Anderson GE, Francis RS, Goetz FC (1981) Vascularized segmental transplantation of the pancreas in insulin-dependent patients: hormonal and metabolic effects of an endocrine graft. Ann Intern Med 95:537-541

Voruganti LNP, Sells RA (1989) Quality of life of diabetic patients after combined pancreatic-renal transplantation. Clin Transplantation 3:78-82

Ms. C. Zehrer, R.N., M.S. University of Minnesota Hospital and Clinic Box 504 UMHC Minneapolis, MN 55455

USA 